University of Nebraska - Lincoln

DigitalCommons@University of Nebraska - Lincoln

Faculty Publications from the Department of Electrical \& Computer Engineering, Department Electrical and Computer Engineering

2011

\title{
Risk-Based Failure Mode and Effect Analysis for Wind Turbines (RB-FMEA)
}

\author{
Salman Kahrobaee \\ University of Nebraska-Lincoln \\ Sohrab Asgarpoor \\ University of Nebraska-Lincoln, sasgarpoor1@unl.edu
}

Follow this and additional works at: https://digitalcommons.unl.edu/electricalengineeringfacpub

Part of the Electrical and Computer Engineering Commons

Kahrobaee, Salman and Asgarpoor, Sohrab, "Risk-Based Failure Mode and Effect Analysis for Wind Turbines (RB-FMEA)" (2011). Faculty Publications from the Department of Electrical and Computer Engineering. 172.

https://digitalcommons.unl.edu/electricalengineeringfacpub/172

This Article is brought to you for free and open access by the Electrical \& Computer Engineering, Department of at DigitalCommons@University of Nebraska - Lincoln. It has been accepted for inclusion in Faculty Publications from the Department of Electrical and Computer Engineering by an authorized administrator of DigitalCommons@University of Nebraska - Lincoln. 


\title{
Risk-Based Failure Mode and Effect Analysis for Wind Turbines (RB-FMEA)
}

\author{
Salman Kahrobaee and Sohrab Asgarpoor \\ Department of Electrical Engineering \\ University of Nebraska Lincoln
}

\begin{abstract}
Failure Mode and Effect Analysis (FMEA) has already been used as a qualitative measure for identifying failure modes and causes, in order to mitigate the effects of failure in different sectors of power systems. This paper presents a quantitative approach called Risk-Based-FMEA, based on the failure probabilities and incurred failure costs instead of rating scales. As a case study, this approach has been applied to a direct drive wind turbine. The results show that the definition of failure modes priorities based on their contribution to the total failure cost of the wind turbine is more realistic and practical than the common FMEA approach. Using MS Excel spreadsheet platform, the proposed method can be generalized for different types of wind turbines. In addition, the effective failure cost factors are investigated through sensitivity analysis, by which the wind turbine owner can determine the suitable approach to reduce the total failure cost.
\end{abstract}

Index Terms-RB-FMEA, wind turbine, failure mode, criticality, cost.

\section{INTRODUCTION}

Recently, renewable energy has proven to be the key solution for the energy crisis in the fast growing and populated world which continues to deplete fossil-based resources [1]. Wind energy is a justifiable resource among the renewables because of technological improvements and consequently cost reduction of wind power generation in recent years [2]. In United States, wind generation installed capacity reached to more than $40,000 \mathrm{MW}$ by the end of 2010, and continues to increase based on the US renewable energy portfolio [3].

Integration of large capacities of wind farms, on the other hand, introduces new challenges in terms of output power variability of the wind turbines due to stochastic parts failures and wind speed changes [4, 5]. As a result, these uncertainties can cause complications for the owners of the wind farms in order to estimate the day-ahead energy generation inquired by the market, where, off estimation, imposes penalties to them. Therefore, reliability evaluation and proper maintenance scheduling using probabilistic techniques is indispensable to predict the expected energy not served, and to minimize the loss of the wind turbines failures and unavailability [6]. Moreover, it will provide more power to the market and increases the profit margin of wind power generation.

Many studies have been conducted to evaluate the reliability of wind farm as the integrated part of the grid [79]. Some of these studies have addressed the individual wind turbine reliability modeling, and investigated the major factors contributing to the total failure of the turbine $[4,10]$. The wind turbine reliability studies are essentially critical in the design stage of the wind power generation systems. Each year, manufacturers introduce new types of wind power conversion systems based on technological improvements. A detailed reliability study for each individual design would assist them in prioritizing their investment in material enhancement and proper adjustments in the turbine structure.

Another valuable outcome of the reliability study for individual wind turbines is exposed in the operation stage. Based on this type of study, the wind farm owner may adjust the manufacturer's primary maintenance recommendations in order to increase their performance and eventually their profits. The adjustments are dependent on the wind farm's specific operation conditions such as the location, site weather, power purchase rate, and available facilities.

Failure Mode and Effect Analysis (FMEA) is a proactive process to determine several key potential failures in the system through the comparison of some predefined factors, and as a result, it helps increase the availability of that system $[11,12]$. This process has been used on almost any equipment from cars to space shuttles, and as of the last decade wind turbines have been briefly studied [13-15].

Although FMEA has proven to be essential in various industries, there are some shortcomings with this method. Inherently, FMEA is a qualitative approach which results in calculation of an index known as Risk Priority Number (RPN) for each part of the system. The value of RPN for a single part is not self-informative and it only can be used in comparison with other parts' RPNs for prioritization purposes. This method also requires scaling of different affecting parameters and so far, there is no one- fits-all solution for rating scale definition. As for the wind turbine, researchers have to define their own rating scales or adopt other developed tools and standards which are not specifically designed for wind turbines, and, so, the result may not necessarily represent the true priorities of the wind generation system [15]. 
This paper proposes an extension to the FMEA method which incorporates the cost associated with each failure mode, hence called Risk-Based FMEA (RB-FMEA). Limited use of this concept has been considered in previous literatures $[16,17]$. The authors believe it is more realistic to consider cost which is the common language among different sectors of turbine design, operation and maintenance. In addition, it is a quantitative approach whose outcome is proportional to the wind turbine performance and so can easily be compared with costs of different maintenance strategies or design improvements in order to make an optimum decision. One of the advantages of this proposed strategy is its simplicity, where it is implemented using Microsoft Excel worksheets and can be easily edited or adapted for use by manufacturers of different types of wind turbines.

\section{FMEA PROCESS}

This section describes the strategy for FMEA and the improvements achieved by including cost in the study.

FMEA is considered as a process of ranking the most critical parts of a system for efficient resource allocation to higher priorities. In the literature, there are few FMEA studies reported on wind turbines. In FMEA study, after determination of the failure modes, the main calculation procedure comprises of three steps:

1) The probabilities of the failure modes occurrences need to be determined. These may be obtained from the previous data for the failed parts. These probabilities are then categorized and assigned a scaling number; with the lowest number for the least probable category.

2) The rate of severity of each failure mode is assigned and scaled due to the consequences of the failure and the amount of damage to the equipment.

3) Another scale number is assigned to the fault detection possibility; with the lowest number to the most likely detection of the failure.

The outcome of this study is the Risk Priority Number (RPN) which is calculated by multiplying all these three scale numbers. The RPNs are then ranked in order of importance.

As discussed earlier, there are some shortcomings with using FMEA. Specifically there are a variety of wind turbine types with different structures and it is not possible to assign the same set of scale numbers for all of them. For example, the damage to a synchronous generator in a direct drive wind turbine is generally more severe and more costly than an induction generator in a fixed speed wind turbine. Another issue with the current calculation method is that, the evaluated RPN doesn't inherently discriminate between a highly severe but low probable failure mode and a less severe with higher occurrence probability mode.

In order to overcome these problems, this paper proposes a definition based on the cost consequences of wind turbines failure modes. The new definition is more realistic and practical which allows direct comparison of different wind turbines. In addition, this paper provides a simple calculation tool in spreadsheet format which enables wind farm owners to edit the input data and perform their own RB-FMEA.

\section{PRoposed RB-FMEA PRocEdURE}

Given the failure modes, the proposed RB-FMEA procedure for wind turbine is as follows:

- Determine the probability of occurrence of each failure mode given that the wind turbine has failed, $P_{F}$, based on the historical data.

- Determine the probability of not detecting the failure, $P_{N D}$.

- Calculate the cost consequence of the failure, $C_{F}$.

- Evaluate the risk of each failure mode, called Cost Priority Number (CPN), by multiplying the probabilities and the cost calculated in previous steps.

$$
C P N(i)=P_{F}(i) \times P_{N D}(i) \times C_{F}(i)
$$

where, " $i$ " is the index of $\mathrm{i}^{\text {th }}$ failure mode. The calculated $\mathrm{CPN}$ is expressed in dollars and can be easily compared for different failure modes.

$P_{N D}$ is calculated by dividing the number of actual failures, $N_{F}$, to the total Number of Failure Vulnerabilities, $N_{F V}$, as:

$$
P_{N D}(i)=\frac{N_{F}(i)}{N_{F V}(i)}
$$

Number of Failure Vulnerabilities is defined as the sum of number of actual failures and the number of detected possible failures prior to their occurrences, for any given period of time. These risks of failure may be detected during online monitoring, inspection, or maintenance.

The cost of failure, $C_{F}$, is incurred due to the severity of failure consequence. Here, we only consider those consequences that are affecting the wind turbine itself. However, it should be denoted that, the failures may have other consequences endangering the safety of the site crew and neighbor residents which is specific for a given site and have not been included in this study.

Therefore, the cost of failure is defined as:

$$
C_{F}(i)=C_{P}(i)+C_{S}(i)+C_{O}(i)+C_{L}(i)
$$

where, $C_{F}$ is comprised of four major costs. $C_{P}$, is the cost of parts which need to be replaced due to the failure. $C_{S}$, is the cost of service, and it includes all the costs associated with the required facilities and devices due to the failure, such as renting a crane, or transportation, etc. $C_{O}$, represents the opportunity cost, which is the sum of revenues the wind farm owner would have received from selling power generation, in case the failure didn't occur. It can be expressed as:

$$
C_{O}(i)=D_{F}(i) \times \overline{W P}_{\text {out }} \times \overline{E P R}
$$

where, $D_{F}$ corresponds to the duration of failure, and $\overline{W P}_{\text {out }}$ and $\overline{E P R}$ are the average output wind power of turbine, and average energy purchase rate, within this duration, respectively. 
Finally, $C_{L}$ in equation 3 represents the total cost of extra labor required for the repair, and can be expressed as:

$$
C_{L}(i)=D_{F}(i) \times N_{C} \times M H R
$$

In the above equation, $N_{C}$ and $M H R$ are number of repair crew, and man-hour rate, respectively.

While CPN represents a cost based risk factor, it can easily be incorporated in calculation of the total failure cost of the system for any specific duration of interest $\left(D_{\text {Int }}\right)$. The total failure cost can be derived as:

$$
T F C=\sum_{i=1}^{m} N_{F V}\left(i, D_{\text {Int }}\right) \times C P N(i)
$$

Where, $m$ represents the total number of the failure modes, and $N_{F V}\left(i, D_{I n t}\right)$ denotes the number of failure vulnerabilities of failure mode $i$ for the duration of interest. In this paper, the total failure cost for duration of one year is denoted by annual failure cost (AFC).

\section{RB-FMEA FOR WIND TURBINE TECHNOLOGIES}

There has been a variety of wind power generators developed in recent decades. For our RB-FMEA study, various wind turbine structures and their sub-assemblies need to be identified.

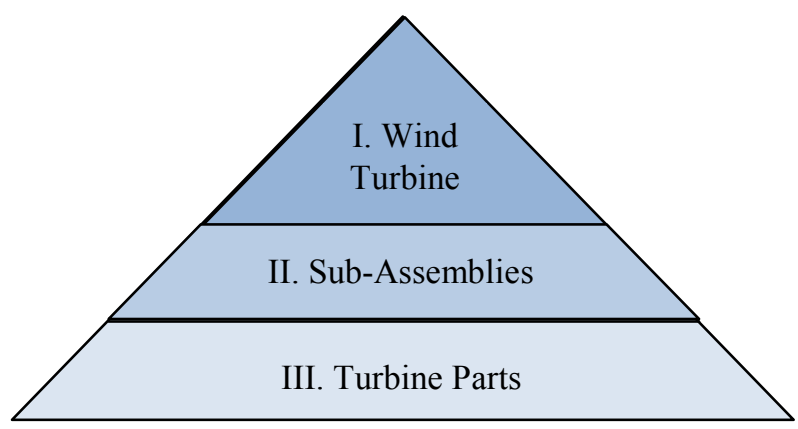

Fig.1. Wind turbine hierarchy for RB-FMECA

The failure of the wind generation system is defined through three levels as shown in Figure 1. The wind turbine stands in the highest level (level I); where, wind turbine subassemblies and parts are divisions of middle (level II) and low (level III) levels respectively.

\section{A. Different wind generation systems, subassemblies and parts}

According to reference [18], wind energy systems can basically be categorized by generator, gearbox, and converter types as shown in Table I.

After recognizing the wind turbine types in level I, a general set of wind turbine sub-assemblies and parts are defined for levels II and III of Figure 1, as presented in Table II.

Apparently, many other parts could be spotted in a wind turbine, if more details were needed. However, for this study, the focus is on the major parts with higher failure probabilities and serious consequences.
TABLE I

\begin{tabular}{|c|c|c|c|}
\hline $\begin{array}{c}\text { Type of } \\
\text { generation system }\end{array}$ & $\begin{array}{l}\text { Turbine } \\
\text { concept }\end{array}$ & Gearbox & Converter \\
\hline \multirow{2}{*}{$\begin{array}{c}\text { Single Cage Induction } \\
\text { Generator (SCIG) }\end{array}$} & Fixed speed & $\begin{array}{l}\text { Multiple } \\
\text { stage }\end{array}$ & - \\
\hline & Variable speed & $\begin{array}{l}\text { Multiple } \\
\text { stage }\end{array}$ & Full scale \\
\hline \multirow{2}{*}{$\begin{array}{l}\text { Permanent Magnet } \\
\text { Synchronous } \\
\text { Generator (PMSG) }\end{array}$} & Variable speed & - & Full scale \\
\hline & Variable speed & $\begin{array}{l}\text { Single or } \\
\text { Multiple } \\
\text { stage }\end{array}$ & Full scale \\
\hline $\begin{array}{c}\text { Doubly Fed Induction } \\
\text { Generator (DFIG) }\end{array}$ & Variable speed & $\begin{array}{l}\text { Multiple } \\
\text { stage }\end{array}$ & $\begin{array}{c}\text { Partial } \\
\text { scale }\end{array}$ \\
\hline $\begin{array}{l}\text { Electrically Excited } \\
\text { Synchronous } \\
\text { Generator (EESG) }\end{array}$ & Variable speed & - & $\begin{array}{l}\text { Partial \& } \\
\text { Full scale }\end{array}$ \\
\hline $\begin{array}{c}\text { Wound Rotor } \\
\text { Induction Generator } \\
\text { (WRIG) }\end{array}$ & $\begin{array}{c}\text { Limited } \\
\text { variable speed }\end{array}$ & $\begin{array}{l}\text { Multiple } \\
\text { stage }\end{array}$ & $\begin{array}{c}\text { Partial } \\
\text { scale }\end{array}$ \\
\hline $\begin{array}{l}\text { Brushless Doubly Fed } \\
\text { Induction Generator } \\
\text { (BDFIG) }\end{array}$ & Variable speed & $\begin{array}{l}\text { Multiple } \\
\text { stage }\end{array}$ & $\begin{array}{l}\text { Partial } \\
\text { scale }\end{array}$ \\
\hline
\end{tabular}

WIND GENERATION SYSTEMS IN MARKET

TABLE II

GENERAL SET OF WIND TURBINE SUB-ASSEMBLIES AND MAIN PARTS

\begin{tabular}{|c|c|}
\hline Sub-assemblies & Main Parts \\
\hline Structure & Nacelle, Tower, Foundation \\
\hline Rotor & Blades, Hub, Air brake \\
\hline Mechanical Brake & Brake disk, Spring, Motor \\
\hline Main shaft & Shaft, Bearings, Couplings \\
\hline Gearbox & $\begin{array}{c}\text { Toothed gear wheels, Pump, } \\
\text { Oil heater/cooler, Hoses }\end{array}$ \\
\hline Generator & Shaft, Bearings, Rotor, Stator, Coil \\
\hline Yaw system & Yaw drive, Yaw motor \\
\hline Converter & Power electronic switch, cable, DC bus \\
\hline Hydraulics & Pistons, Cylinders, Hoses \\
\hline Electrical System & $\begin{array}{c}\text { Soft starter, Capacitor bank, Transformer, } \\
\text { Cable, Switchgear }\end{array}$ \\
\hline Pitch System & Pitch motor, Gears \\
\hline Control system & $\begin{array}{c}\text { Sensors, Anemometer, communication } \\
\text { parts, processor, Relays }\end{array}$ \\
\hline
\end{tabular}

\section{B. Failure modes}

The failure occurs when a device no longer operates the way intended. There are numerous failure modes that can be defined for a complicated assembly like wind turbines. These failure modes can cause partial or complete loss of power generation. Mainly, the key failure modes, which cause complete loss of power generation, are malfunction and major damage of the main parts of the turbine stated in Table II. Other failure modes are less significant and may be surface damage and cracks, oil leakage, loose connection, etc. However, if they are not taken care of, minor failure modes can initiate major failures as well.

Evidently, each one of the failure modes has a root cause, and the probability of that failure mode is directly related to the probability of its root cause. Table III provides different categories for these causes. Human error in this table, refers to the errors occurred during operation or maintenance. 
TABLE III

ROOT CAUSES OF THE FAILURE MODES

\begin{tabular}{|c|c|c|c|}
\hline Weather & Mechanical & Electrical & Wear \\
\hline High wind & Manufacturing and & Grid fault & Aging \\
Icing & material defect & Overload & Corrosion \\
Lightening & Human error & Human error & \\
& External damage & Software failure & \\
\hline
\end{tabular}

\section{Failure probabilities}

Failure probability of each failure mode is calculated from the contribution of that failure mode in the interruption of the wind turbine operation. The limiting factor in FMEA study of wind turbines is that the detailed failure data are not available for all of the failure modes. Today, the number of reports providing statistics on failure probabilities is increasing. Some of these statistics have been categorized based on the capacity of the wind turbines, while some others have been divided according to the type of the wind generation system $[19,20]$.

\section{Failure detection}

There are a variety of ways to detect the probable failure modes as categorized in Table IV.

TABLE IV

MAJOR DETECTION METHODS OF THE FAILURE MODES

\begin{tabular}{|l|l|l|}
\hline Inspection & Condition Monitoring & \multicolumn{1}{|c|}{ Maintenance } \\
\hline Visual & Vibration analysis & Time-Based \\
Olfactive & Oil analysis & Condition-Based \\
Auditive & Infrared thermography & \\
& Ultrasonic & \\
\hline
\end{tabular}

The common ways are through inspection or while the turbine is being maintained. However, the fastest and the most reliable method is condition monitoring which can increase the availability of wind turbine considerably by using online systems. With condition monitoring, the probability of not detecting the failure decreases to the failure probability of the human error or the monitoring system itself.

\section{E. Cost based failure criticality}

As described by equation 3, four different costs should be calculated. The data needed for the cost study include repair or new part expenses, duration of repair, etc, which are specific for each wind turbine type and should be provided by the wind farm owner.

\section{CASE Study}

The proposed RB-FMEA method is applied to a $3 \mathrm{MW}$ direct drive wind turbine. Figure 2 demonstrates the flowchart for the study.

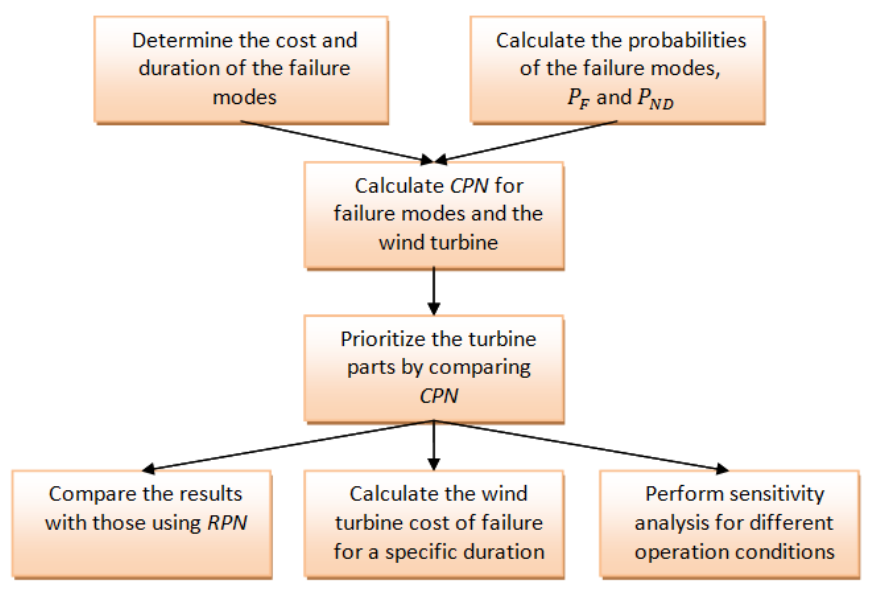

Fig.2. Flowchart for the case study

The required failure probabilities, vulnerabilities, costs, and durations are calculated based on the available data in [19-26]. A spreadsheet was set up using Microsoft Excel, and the result parameters were derived for the wind turbine parts as shown in Table $\mathrm{V}$.

TABLE V

SNAPSHOT OF THE SPREADSHEET FOR RB-FMEA ANALYSIS

\begin{tabular}{|c|c|c|c|c|c|c|c|c|c|c|c|c|c|c|}
\hline 4 & $A$ & $B$ & $\mathrm{C}$ & $\mathrm{D}$ & $E$ & $\mathrm{~F}$ & $\bar{G}$ & $\mathrm{H}$ & 1 & J & K & L & $M$ & $\mathrm{~N}$ \\
\hline & Type of Study & \multirow{2}{*}{$\begin{array}{c}\text { Scale of } \\
\text { Occurrence }\end{array}$} & \multirow{2}{*}{$\begin{array}{l}\text { Scale of } \\
\text { Severity }\end{array}$} & \multirow{2}{*}{$\begin{array}{c}\text { Scale of } \\
\text { Detection }\end{array}$} & \multirow[b]{2}{*}{$R P N$} & \multirow{2}{*}{$\begin{array}{c}\begin{array}{c}\text { Probability } \\
\text { of Failure }\end{array} \\
P_{F}\end{array}$} & \multirow{2}{*}{\begin{tabular}{|c|}
$\begin{array}{c}\text { Probability } \\
\text { of Not } \\
\text { Detection }\end{array}$ \\
$P_{N D}$
\end{tabular}} & \multicolumn{6}{|c|}{ Effect and Severity per failure } & \multirow[b]{2}{*}{$\begin{array}{c}C P N \\
(\$)\end{array}$} \\
\hline 3 & Item Name & & & & & & & $\begin{array}{c}D_{F} \\
\text { (Hours) }\end{array}$ & $\begin{array}{l}C_{p} \\
(\$)\end{array}$ & $\begin{array}{l}C_{S} \\
(\$)\end{array}$ & $\begin{array}{l}C_{L} \\
(\$)\end{array}$ & $\begin{array}{l}C_{0} \\
(\$)\end{array}$ & $\begin{array}{l}C_{F} \\
(\$)\end{array}$ & \\
\hline 4 & Electrical System & 5 & 3 & 4 & 60 & 0.23 & 0.6 & 100 & 10275 & 6450 & 1000 & 6000 & 23725 & 3274.05 \\
\hline 5 & Gearbox & -- & -- & -- & -- & -- & -- & -- & -- & -- & -- & -- & -- & -- \\
\hline 6 & Hydraulic System & 3 & 3 & 4 & 36 & 0.088 & 0.8 & 60 & 1500 & 4050 & 600 & 3600 & 9750 & 686.4 \\
\hline 7 & Control System & 5 & 2 & 7 & 70 & 0.101 & 0.9 & 48 & 2775 & 900 & 480 & 2880 & 7035 & 639.4815 \\
\hline 8 & Blades & 3 & 4 & 4 & 48 & 0.065 & 0.7 & 96 & 30750 & 18375 & 960 & 5760 & 55845 & 2540.9475 \\
\hline 9 & Pitch Mechanism & 3 & 2 & 7 & 42 & 0.041 & 0.9 & 72 & 4800 & 1800 & 720 & 4320 & 11640 & 429.516 \\
\hline 10 & Generator & 5 & 4 & 4 & 80 & 0.198 & 0.7 & 180 & 61500 & 29325 & 180 & 10800 & 101805 & 14110.173 \\
\hline 11. & Yaw System & 3 & 2 & 4 & 24 & 0.065 & 0.8 & 55 & 1950 & 5475 & 550 & 3300 & 11275 & 586.3 \\
\hline 12. & Mechanical Brake & 3 & 3 & 7 & 63 & 0.06 & 0.9 & 72 & 1725 & 4575 & 720 & 4320 & 11340 & 612.36 \\
\hline 13. & Converter & 5 & 3 & 4 & 60 & 0.129 & 0.8 & 48 & 13650 & 1800 & 480 & 2880 & 18810 & 1941.192 \\
\hline 14. & Main Shaft & 2 & 3 & 7 & 42 & 0.009 & 0.9 & 120 & 6150 & 14700 & 120 & 7200 & 28170 & 228.177 \\
\hline 15 & Tower and Structure & 2 & 4 & 7 & 56 & 0.009 & 0.9 & 96 & 27300 & 22050 & 960 & 5760 & 56070 & 454.167 \\
\hline 16 & Other Parts & 2 & 2 & 10 & 40 & 0.005 & 1 & 86 & 3450 & 900 & 860 & 5160 & 10370 & 51.85 \\
\hline
\end{tabular}


For the base condition, it is assumed that for the duration of the failures, the Capacity Factor (CF) of the wind turbine and the EPR have been 0.4 and $5 \phi / \mathrm{kWh}$ respectively.

The resulted CPN column shows that, the generator is ranked the most critical part of the studied direct drive wind turbine followed by electrical system, blades and converter. This analysis can be conducted for any other types of wind turbine and for any operation condition. In addition, by summing up the CPN of all the parts of a turbine, one can estimate the overall CPN of that wind turbine. This number can then be compared with the overall CPNs of other types of wind turbine in order to rank them from criticality perspective. For our study, the overall CPN adds up to $\$ 25.5 \mathrm{k}$.

The calculation of RPN was also included in Table $\mathrm{V}$ for evaluation, and the required parameters were determined using rating scheme of reference [27]. Figure 3 compares the results of RPN and CPN for our study case.

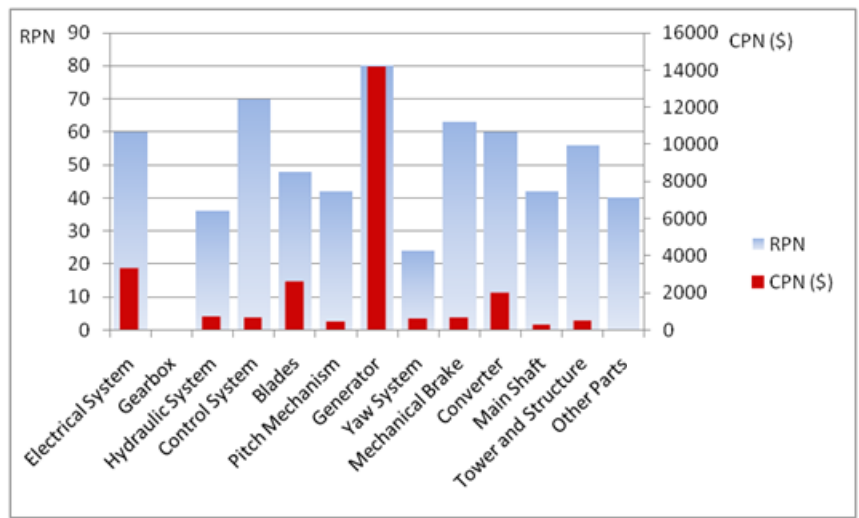

Fig.3. RPN and CPN for major parts of the wind turbine

While two methods are in agreement about the generator being the most critical part of the direct drive wind turbine, the building blocks of RPN are discrete and qualitative, and therefore cannot represent the strength of criticality effectively. Nevertheless, CPN is calculated based on the actual costs, and, so, is more rational to be looked up to for making adjustments on design, operation and maintenance of wind turbines.

In order to estimate the Annual Failure Cost of this direct drive wind turbine, Equation 6 was used and the results are shown in Figure 4.

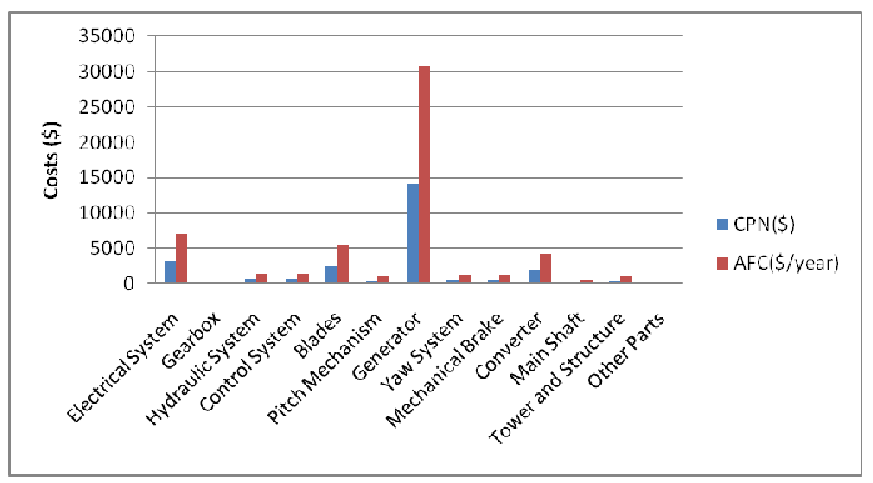

Fig.4. AFC and CPN for major parts of the wind turbine
In fact, each part's CPN has been multiplied by its Failure Vulnerability as a weighting factor. Failure Vulnerability specifies how many times per year each of the wind turbine parts has been detected with a risk of failure or has actually failed.

Based on the results, the total AFC of the wind turbine is $\$ 55.5 \mathrm{k}$, which implies an overall failure vulnerability of 2.17 per year for our wind turbine.

\section{SENSITIVITY ANALYSIS}

As mentioned earlier, the results of RB-FMEA analysis is dependent on a number of parameters such as $C_{P}, D_{F}, E P R$, $C F, P_{N D}$, etc. The effects of some of these parameters are investigated in this section.

One of the key parameters affecting the total cost of failure is duration of the failure. Generally, the repair of a wind turbine may be delayed due to lack of parts in the inventory, unavailability of the required facility, adverse weather condition, or human error. Therefore, the annual failure cost was determined by increasing the imposed delay as shown in Figure 5.

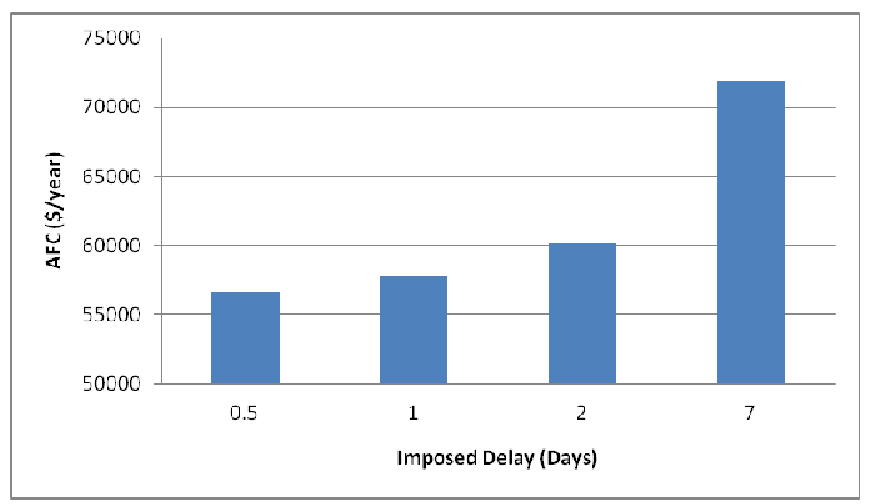

Fig.5. Sensitivity of the turbine AFC to the additional imposed delay

The results of this study may suggest the reasonable amount of money to be spent in order to avoid these types of delays. For example, one week of delay in repairs escalates the initial annual failure cost of $\$ 55.5 \mathrm{k}$ to more than $\$ 70 \mathrm{k}$. Hence, any solution for delay prevention, like recruiting more labor or providing extra tools, would work if its cost is less than $\$ 14.5 \mathrm{k}$ per year. The above results are derived according to our previously selected base values for EPR and CF. However, the proposed approach is flexible for different wind turbines and operation conditions.

In fact, $\mathrm{CF}$ and EPR are two major parameters which vary due to the wind speed and the location of the site, and therefore, alter the cost of opportunity during the downtime of the turbine. Figure 6 displays the effect of these two parameters on the annual failure cost of the wind turbine in our case study. 


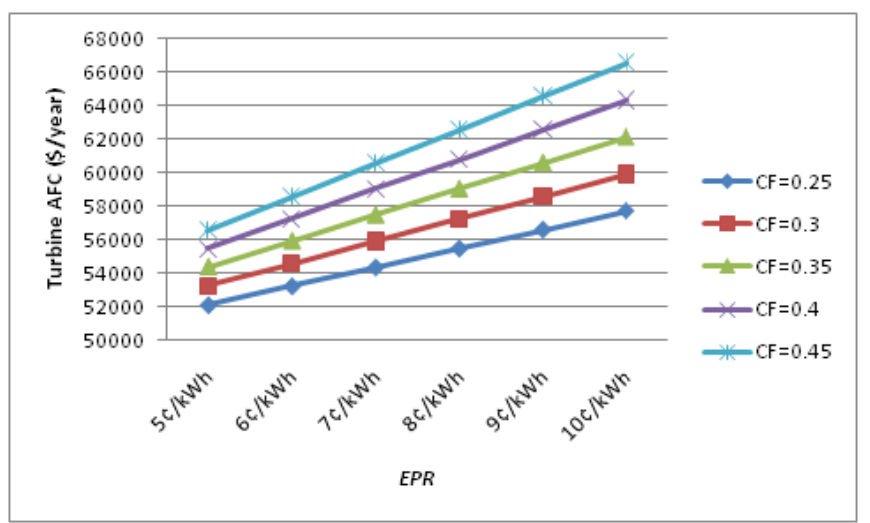

Fig.6. Sensitivity of the turbine AFC to the EPR and CF

According to these results, annual cost of failure may change more than $25 \%$, due to the change in the energy price and the wind speed.

In another study, the effects of cost of the wind turbine parts in the marketplace are investigated. National Renewable Energy Laboratory (NREL) has provided percentages of commodities making up each main part of a wind turbine [21]. Using these categories, this paper has incorporated Producer Price Index (PPI) as described in the U.S. Department of Labor and U.S. Bureau of Labor Statistics Report [28], to estimate the rate of increment in costs of the wind turbine parts for duration of Jan.2010 to Jan.2011. The highest rates were determined to be due to change in costs of iron castings and drive motors. Then, these changes have been applied to Table $\mathrm{V}$ in order to determine the AFC. Considering the costs of the parts in 2010 as the base values, the results shown in Figure 7 indicate that the annual failure cost of the studied wind turbine will increase by $1.7 \%$ in 2011 .

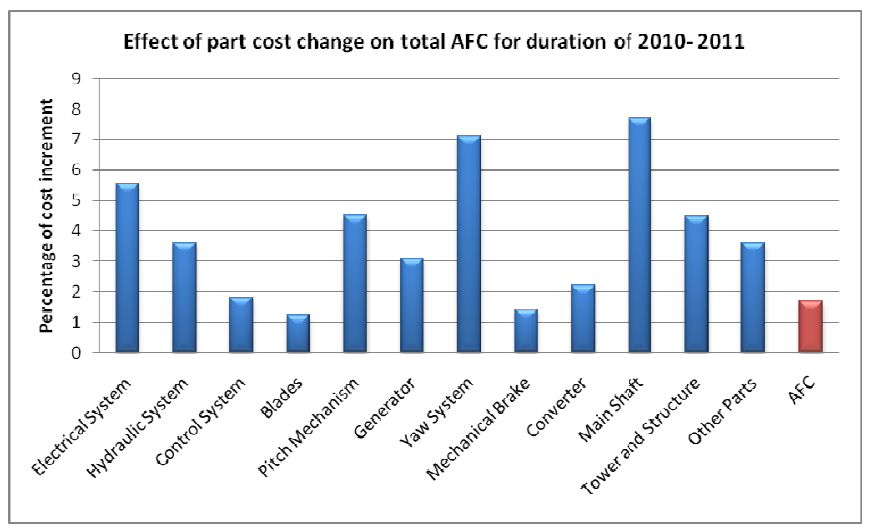

Fig.7. Percentage of cost increase due to the inflation from 2010 to 2011

One effective approach to reduce the failure cost is by improving the failure detection system. As stated before, for the case study of this paper, "generator" has the highest priority to start with. Figure 8 illustrates the total savings in turbine's AFC, by 10 percent improvement in the generator fault detection system under different operation conditions.

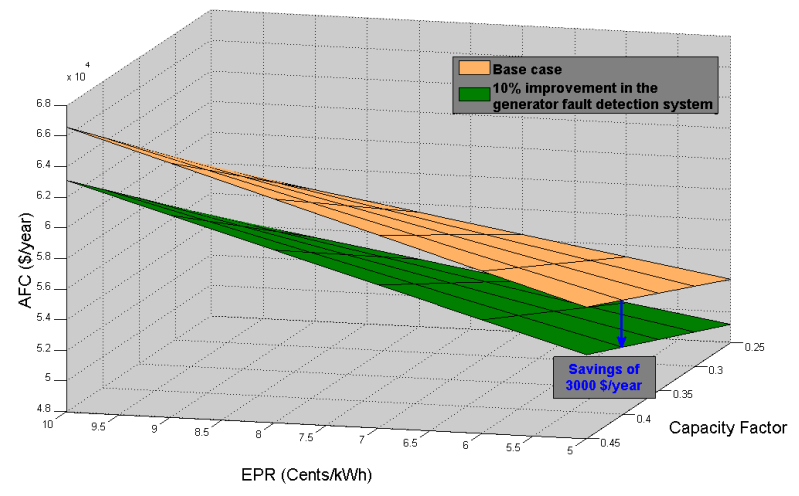

Fig.8. Annual failure cost before and after 10 percent improvement in the generator fault detection system

As an example, for the capacity factor of 0.4 and EPR of 5 cents $/ \mathrm{kWh}$, the total savings are approximately $\$ 3000$ per year. This implies that a condition monitoring system, which costs less than this amount and can guarantee the ten percent improvement in fault detection, is reasonable to be purchased in this case.

\section{CONCLUSION}

This paper introduced a new quantitative approach for the FMEA study of the wind turbines based on their failure modes contribution to the total failure cost. This method was applied to a $3 \mathrm{MW}$ direct drive wind turbine as a case study, and results illustrate a more realistic identification of credible failure modes priorities. The values of CPN introduced in this paper, not only specify the critical failure modes, but they can also be utilized for calculation of total failure costs of wind turbines for duration of interest. Complexity of using special software was avoided by using MS Excel spreadsheet platform, and therefore, this method can simply be employed for different types and locations of the wind turbines. Finally, sensitivity analyses were performed in order to determine the impact of various parameters on AFC of wind turbines.

\section{ACKNOWLEDGMENT}

The authors are grateful to the Nebraska Center for Energy Sciences Research for their support of this project.

\section{REFERENCES}

[1] International energy outlook 2010. U.S. Energy Information Administration. Available: www.eia.gov/oiaf/ieo/index.html.

[2] Renewable fuels module. U. S. Energy Information Administration Report: DOE/EIA-0554(2010).

[3] U.S. wind industry year-end 2010 market report. American Wind Energy Association, January 2011.

[4] Spinato, 20091201, Reliability of wind turbine subassemblies. IET Renewable Power Generation 3(4), pp. 387.

[5] P. J. Tavner, R. Gindele, S. Faulstich, B. Hahn and M. W. Whittle. Study of effects of weather and location on wind turbine failure rates. Presented at EWEC 2010.

[6] Jesse A. Andrawus, John Watson and Mohammed Kishk. 20070101, Modelling system failures to optimise wind turbine maintenance. Wind Eng 31(6), pp. 503. 
[7] P. Hu, R. Karki and R. Billinton. 2009, Reliability evaluation of generating systems containing wind power and energy storage. Generation, Transmission \& Distribution, IET 3(8), pp. 783-791.

[8] S. Kahrobaee and S. Asgarpoor. Short and long-term reliability assessment of wind farms. Presented at North American Power Symposium (NAPS), 2010.

[9] H. Lingling and Fu Yang. Reliability evaluation of the offshore wind farm. Presented at Power and Energy Engineering Conference (APPEEC), 2010 Asia-Pacific.

[10] H. Guo, S. Watson, P. Tavner and J. Xiang. 20090601, Reliability analysis for wind turbines with incomplete failure data collected from after the date of initial installation. Reliab. Eng. Syst. Saf. 94(6), pp. 1057.

[11] D. H. Stamatis. 2003, Failure Mode and Effect Analysis: FMEA from Theory to Execution .

[12] R. J. Mikulak, R.McDermott and M. Beauregard. 2008, the Basics of FMEA (2nd ed.) .

[13] W. E. Klein and V.R. Lali. Model-OA wind turbine generator: Failure modes and effects analysis. Presented at Annual Reliability and Maintainability Symposium, 1990.

[14] J. Andrawus, J. Watson, M. Kishk and A. Adam. 20060101, The selection of a suitable maintenance strategy for wind turbines. Wind Eng 30(6), pp. 471.

[15] P. J. Tavner, A Higgins, H. Arabian, H. Long and Y. Feng. Using An FMEA Method to Compare Prospective Wind Turbinee Design Reliabilities Presented at European Wind Energy Conference (EWEC 2010).

[16] A. Hassan, I. Dayarian, A. Siadat and J. -. Dantan. Cost-based FMEA and $\mathrm{ABC}$ concepts for manufacturing process plan evaluation. IEEE Conference on Cybernetics and Intelligent Systems, 2008.

[17] C. M. Spencer and S. J. Rhee. Cost based failure modes and effects analysis (FMEA) for systems of accelerator magnets. Particle Accelerator Conference, 2003. PAC 2003.

[18] H. Li and Z. Chen. 2008, Overview of different wind generator systems and their comparisons. Renewable Power Generation, IET 2(2), pp. 123-138.

[19] E. Echavarria, B. Hahn, G. J. W. van Bussel and T. Tomiyama. 20080801, Reliability of wind turbine technology through time. Journal of Solar Energy Engineering 130(3), pp. 031005.

[20] J. Ribrant and L. Bertling. Survey of failures in wind power systems with focus on Swedish wind power plants during 1997-2005 IEEE Power Engineering Society General Meeting, 2007.

[21] L. Fingersh, M. Hand and A. Laxson. 2006, Wind turbine design cost and scaling model. NREL. Available: http://www.nrel.gov/wind/pdfs/32495.pdf.

[22] H. Polinder, F. F. A. van der Pijl, G. -. de Vilder and P. J. Tavner. 2006, Comparison of direct-drive and geared generator concepts for wind turbines. Energy Conversion, IEEE Transactions on 21(3), pp. 725-733.

[23] R. Poore and C. Walford. 2008, Development of an operations and maintenance cost model to identify cost of energy savings for low wind speed turbines. NREL. Available: http://www.nrel.gov/docs/fy08osti/40581.pdf.

[24] R. Poore and T. Lettenmaier. 2003, Alternative design study report: WindPACT advanced wind turbine drive train designs study. NREL. Available: http://www.nrel.gov/docs/fy03osti/33196.pdf.

[25] Deok-je Bang, Henk Po Under, G. Shrestha and J. A. Ferreira. Promising direct-drive generator system for large wind turbines. Presented at Wind Power to the Grid - EPE Wind Energy Chapter 1st Seminar, 2008. EPE-WECS 2008.

[26] G.J.W. van Bussel and M.B. Zaaijer. Reliability, availability and maintenance aspects of large-scale offshore wind farms, a concepts study. Presented at Marine Renewable Energy Conference.

[27] H. Arabian-Hoseynabadi, H.Oraee and P.J. Tavner. 20100901, Failure modes and effects analysis (FMEA) for wind turbines. International Journal of Electrical Power \& Energy Systems 32(7), pp. 817.

[28] U.S. Department of Labor and U.S. Bureau of Labor Statistics; PPI Detailed Report, data for January 2011, Vol. 15, No. 1. 